children, overt vitamin $D$ deficiency rickets was diagnosed concomitantly with their coeliac disease. The ages at diagnosis of these three were 7, 10, and 11 months; their ages when first symptomatic were 4,9 , and 7 months. In the other six cases, where no overt rickets was recorded, the ages at diagnosis were $7,18,19,21$ months, 2 years 4 months, and 4 years 10 months, the ages when first symptomatic being $4,16,6,8,8$, and 5 months. We are now analysing the time sequences of coeliac disease, rickets and, according to the teeth affected and the extent of hypoplasia, the possible concordance or discordance with the time of mineralisation of the affected areas in the diseased teeth. We feel that rickets, even when not clinically or biochemically evident, as is often the case in untreated coeliac disease, could be relevant to the development of enamel hypoplasia.

D H SHMERLING AND M SACHER Kinderspital Zürich, University Department of Paediatrics, Division of Paediatric Gastroenterology, Steinwiesstrasse 75, CH-8032 Zürich

B WIDMER AND E D BEN ZUR Dental Institute of the University of Zurich, Plattenstrasse 11, CH-8028 Zurich

\section{Neonatal effects of maternal therapy with tricyclic antidepressant drugs}

Sir,

We read with interest the letter by Ben Musa and Smith (Archives, 1979, 54, 405) on withdrawal symptoms, mainly instability of body temperature and jitterness, in a neonate affected by maternal clomipramine intake.

In 1972 we reported on three term infants born of mothers who took imipramine during pregnancy. ${ }^{1}$ Transient, alternating episodes of hypokinesia and jerky movements were seen in all three. One baby convulsed on day 2. Transient tachypnoea and poor peripheral circulation were also common findings. In 1973 Webster ${ }^{2}$ described another baby with similar symptoms. On the other hand, Shearer et al. ${ }^{3}$ observed pronounced urinary retention in a neonate secondary to maternal ingestion of nortriptyline. Our third patient too, was irritable and showed 'belly dance' movements before voiding. Although hypothermia is only mentioned by Ben Musa and Smith, it is noteworthy that Wattiaux-De Coninck et al. ${ }^{4}$ could demonstrate the fixation of radioactive imipramine on mitochondria. The action of imipramine on oxidative phosphorylation, and hence on thermogenesis, could explain the occurrence of hypothermia in some of the affected neonates.

Present data suggest that tricyclic antidepressant drugs, given to the mother during pregnancy, may impair the adaptation of the neonate to extrauterine life.

\section{References}

1 Eggermont E, Raveschot J, Deneve V, Casteels-VanDaele M. The adverse influence of imipramine on the adaptation of the newborn infant to extrauterine life. Acta Paediatr Belg 1972; 26: 197-204.

2 Webster P A C. Letter: Withdrawal symptoms in neonates associated with maternal antidepressant therapy. Lancet 1973 ; 2 : 318-9.

3 Shearer W T, Schreiner R L, Marshall R E. Urinary retention in a neonate secondary to maternal ingestion of nortriptyline, $J$ Pediatr 1972; 81: 570-2.

4 Wattiaux-De Coninck S, Dubois F, Wattiaux R. Effet de l'imipramine sur les mitochondries de foie de rat. Arch Int Physiol Biochim 1974; 82: 209.

$$
\begin{array}{r}
\text { E EGGERMONT } \\
\text { Kinderkliniek, } \\
\text { Academisch Ziekenhuis Gasthuisberg, } \\
3000 \text { Leuven, Belgium }
\end{array}
$$

\section{Diagnosis and management of folate deficiency in low birthweight infants}

Sir,

I read with interest the paper by Strelling et al. (Archives, $1979,54,271)$. Although the erythrocyte folate levels suggested folate deficiency, the babies were too young to have megaloblastic anaemia. Herbert ${ }^{1}$ showed that serum folate level decreases early (about 7 weeks) and it takes nearly 19 weeks for the real megaloblast to appear in the bone marrow.

The mean reticulocyte count for the babies was $2.64 \%$ (range 0 to 6, Table 1) which would not be expected in real megaloblastic anaemias. The rise of $\mathrm{Hb}$ and haematocrit values (such as 0.3 and $1 \%$ ) in 2 to 4 weeks' treatment are well below a response to treatment. ${ }^{2}$

Because of the feeding history (including iron supplement), the ages of the babies, and the slightly high reticulocyte count for age, I should like to see studies (such as hydrogen peroxide test and vitamin E levels) to exclude vitamin $\mathrm{E}$ deficiency. It is well known that megaloblastic changes of erythroid precursors occur in haemolytic anaemias regardless of the cause.

\section{References \\ 1 Herbert V. Megaloblastic anemias. Modern Medical Monographs. New York: Grune \& Stratton, 1959: 162. \\ 2 Herbert V. Current concepts in therapy. Megaloblastic anemia. $N$ Engl J Med 1963; 268: 201-3, 368-71. \\ SINASI OZSOYLU Institute of Child Health, Hacettepe University, Ankara 11191, Turkey}

Drs Strelling and Goodall comment:

Professor Ozsoylu expresses doubts on theoretical grounds that our patients could have had megaloblastic anaemia related to folate deficiency when aged only 5 to 


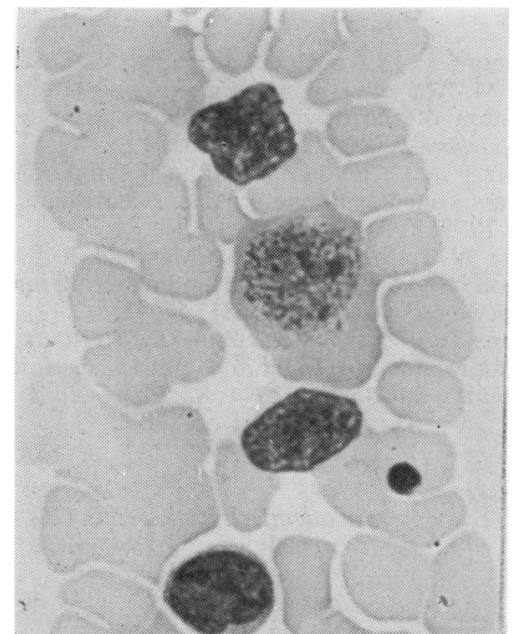

Figure. The centre of this field shows a finely stippled haemoglobinised megaloblast. Buffy-coat smear from

Case 2. $\times$ 900. Stained Leishman.

12 weeks. We should like to reassure him that the megaloblastic changes were unequivocal. The figure (Case 2) shows an undoubted megaloblast which was fully haemoglobinised. This was one of 82 such cells found in a buffy-coat smear made from approximately $50 \mu \mathrm{l}$ blood. The time-scale at which a poor folate intake produces megaloblastosis is very different when a healthy adult physician ${ }^{1}$ is compared with rapidly growing tiny babies whose folate requirements may be relatively much greater. ${ }^{2}$ The megaloblastic preterm infants described by Gray and Butler ${ }^{3}$ were even younger ( 3 to 6 weeks) and other affected babies have been under 12 weeks. ${ }^{4-5}$

We found, as have others, ${ }^{6}$ that a mild reticulocytosis was common in preterm infants in the first 3 months and was unrelated to megaloblastosis. Even so, the mean value $(2.6 \%)$ in our groups of both normoblastic and megaloblastic infants was below that reported by Oski and Barness, ${ }^{7}$ and Ritchie et al. ${ }^{8}$ in infants with haemolytic anaemia due to vitamin E deficiency, namely 8.2 and $6 \cdot 1 \%$ respectively.

The rate at which $\mathrm{Hb}$ rose after treatment with folic acid would be modified by physiological factors in infancy, such as growth and concomitant expansion of plasma volume, and should not be compared with that expected in an adult. Nevertheless, the falling $\mathrm{Hb}$ in each affected infant was invariably reversed after folic acid, even though in some the dose was probably suboptimal.

We are aware that lack of vitamin E has been suggested as a cause of megaloblastic anaemia in malnourished infants but even in the cases described by Majaj et al. ${ }^{9}$ folate deficiency was not completely excluded. Perhaps lack of vitamin E may affect the uptake of folate through cell membranes although in the vitamin E-deficient infants described by Oski and Barness, ${ }^{7}$ and Ritchie $e t$ al. ${ }^{8}$ the bone marrows examined were normoblastic.
In our infants treatment with folic acid but no other addition to diet was followed within a few days by complete normoblastic change associated with a reticulocyte response. As our facts do not fit with Professor Ozsoylu's theories, we suggest the theories be changed to fit the facts.

\section{References}

1 Herbert V. Experimental nutritional folate deficiency in man. Trans Assoc Am Physicians 1962; 75: 307-20.

2 Shojania A M, Hornady G. Folate metabolism in newborns and during early infancy. II. Clearance of folic acid in plasma and excretion of folic acid in urine by newborns. Pediatr Res 1970; 4: 422-6.

3 Gray O P, Butler E B. Megaloblastic anaemia in premature infants. Arch Dis Child 1965; 40: 53-6.

4 Ghitis J, Canosa C. Letter: Folate and $B_{12}$ serum levels in premature infants, with a note on milk folate. $J$ Pediatr 1965; 67: 701-2.

5 Vanier T M, Tyas J F. Folic acid status in premature infants. Arch Dis Child 1967; 42: 57-61.

- Wolff J A, Goodfellow A M. Hematopoiesis in premature infants with special consideration of the effect of iron and of animal-protein factor. Pediatrics 1955; 16: 753-62.

7 Oski F A, Barness L A. Vitamin E deficiency: a previously unrecognised cause of hemolytic anemia in the premature infant. $J$ Pediatr 1967; 70: 211-20.

8 Ritchie J H, Fish M B, McMasters V, Grossman M. Edema and hemolytic anemia in premature infants. $N$ Engl J Med 1968; 279: 1185-90.

9 Majaj A S, Dinning J S, Azzam S A, Darby W J. Vitamin $E$ responsive megaloblastic anemia in infants with protein-calorie malnutrition. Am J Clin Nutr 1963; 12: 374-9.

M K Strelling Department of Paediatrics, Plymouth General Hospital, Plymouth PL4 8QQ. Devon

H B Goodall Department of Pathology, Ninewells Hospital, Dundee, Angus

\section{Sodium nitroprusside and RDS- primum non nocere}

Sir,

There have been two reports on the use of sodium nitroprusside (NaNP) to reduce pulmonary vascular resistance in severe respiratory distress syndrome (RDS). ${ }^{1-2}$ This new indication for an old drug represents an innovative pharmacological approach to the treatment of pulmonary hypertension in the newborn. However, several aspects of this drug must be evaluated before the apparent success reported leads to widespread use in nurseries. As most neonatal therapeutic tragedies have occurred due to altered drug metabolism and disposition in the newborn infant, this aspect needs to be investigated urgently. 